\title{
Adsorption of organic matter by inorganic particulate in air pollution
}

\author{
V. Villas-Boas ${ }^{1}$, L. Moratelli ${ }^{1}$, I. Nascimento ${ }^{1}$, R. M. Dallago ${ }^{2}$, \\ R. Dellanora ${ }^{2}$, A. L. Loureiro ${ }^{3}$, P. Artaxo $^{3}$, E. Ribeiro Lovatel ${ }^{1}$, \\ N. C. Vieceli ${ }^{1} \&$ E. Müller Cardoso ${ }^{1}$ \\ ${ }^{I}$ Physics and Chemistry Department, University of Caxias do Sul, \\ RS-Brazil \\ ${ }^{2}$ Chemistry Department, URI - campus de Erechim, RS-Brazil \\ ${ }^{3}$ Physics Institute, University of São Paulo, SP-Brazil
}

\begin{abstract}
The main objective of this work was the semi-quantitative evaluation of the influence of the concentrations of fine and coarse particulate matter $\left(\mathrm{PM}_{2.5}\right.$ and $\mathrm{PM}_{10}$ ) and black carbon (BC) on the organic compound concentrations in the atmosphere of Caxias do Sul, a city in Rio Grande do Sul, the southernmost state of Brazil. The collection of the samples was carried out between August of 2007 and January of 2008. The periodic replacement of the cartridges and sampling filters was performed every other day ( $48 \mathrm{~h}$ sampling). An active sampler was used for the collection of the inorganic particulate matter, that means, $\mathrm{PM}_{2.5}$ and $\mathrm{PM}_{10}$ were sampled using stacked filter units that collect fine $(\mathrm{d}<2.5 \mu \mathrm{m})$ and coarse $(2.5 \mu \mathrm{m}<\mathrm{d}<10 \mu \mathrm{m})$ particulate matter. The organic material was collected by a previously treated cotton cartridge. Both samplings (inorganic and organic matter) were performed at the same time and sampling point, with division of the air flux. The air was forced to pass through the two samplers by a vacuum pump. The inorganic particulate matter was characterized by gravimetry and reflectance. The tentative identification of the organic compounds was obtained by gas chromatography with mass spectrometry detection (GC-MS). The preliminary results suggest an inverse relation among the $\mathrm{PM}_{10}$ concentration and the amounts of some organic compounds like $1 \mathrm{H}$-indene, neridol and diethyl hexylphthalate. On the other hand, the maximum quantity of eburnamonine was detected at the same time as the maximum concentrations of
\end{abstract}


BC. No correlations were found between the $\mathrm{PM}_{2.5}$ concentrations and the amounts of organic compounds, in the samples studied.

Keywords: air pollution, organic matter, particulate, GC/FID.

\section{Introduction}

In an urban area, in addition to the natural components present in the troposphere, pollutant or not-pollutant particles and gases are launched into the atmosphere, that, under different meteorological conditions, such as pressure, temperature, humidity and solar radiation, suffer reactions forming other pollutants that are added to those already emitted. These additional substances contribute to the aggravation of the pollution. The volatile organic compounds (VOCs) and the pollutant gases present in the atmosphere, coming from vehicles and/or industries, can be toxic to the health of the population and harmful to the environment [1-4].

Mountain cities like Caxias do Sul usually attract many visitors and are attractive for the migration of inhabitants of other cities that hope to find there, among other things, a pleasant climate and the healthful air characteristic. However, currently, not even cities considered environmentally healthful can be free of significant environmental contamination, mainly in regard to air quality. Caxias do Sul is situated between 760 and $800 \mathrm{~m}$ above sea level, at latitude $29.168^{\circ}$ and a longitude $-51.179^{\circ}$, with an area of $1,558.4 \mathrm{~km}^{2}$, and a subtropical climate. Caxias do Sul is the second metalworking center of the country and the most important one in the state of Rio Grande do Sul. It has a population of about 400,000 inhabitants and had, in 2007, according to the data of the Brazilian Institute of Geography and Statistics (IBGE) more than 4,000 transformation industries. Each inhabitant generates between 1 and $1.5 \mathrm{~kg}$ of solid residues per day. Still according to IBGE, in 2007 the fleet of automobiles was about 150,000 vehicles. On account of this increased growth, on some days of the year, it is already possible to see signs of thermal inversion layers (with dense fog formation) and, at some points in the city, awkward odors occur, probably the result of increased urbanization.

Although the signs of atmospheric pollution are already apparent and, at the academic level, there already exists an increasing interest in the evaluation of the level of atmospheric pollution in the city, up to the present moment, no study has been carried out in this direction. In this context, this work presents a semiquantitative study of the main organic and inorganic pollutants present in the atmosphere of Caxias do Sul, mainly those that can be associated with automotive and industrial emissions.

\section{Materials and methods}

\subsection{Sampling point}

The collection equipment was installed at the José Gazola School of Professional Education (SENAI) in the São José neighborhood. This neighborhood is known 
mainly for its intense industrial activity and also for the existence of a branch of the Enrique Luis Roessler State Foundation for Environmental Protection (FEPAM). In general, FEPAM carries out $\mathrm{SO}_{2}$ and $\mathrm{O}_{3}$ analyses via ultraviolet fluorescence and $\mathrm{PM}_{10}$ via beta radiation (http://www.fepam.rs.gov.br/ qualidade/boletim_ar_automatica_detalhe.asp). The air samplings were carried out between August of 2007 and January of 2008.

\subsection{Inorganic and organic particulate matter sampling}

The inorganic and organic samplers were connected through a hose with a metallic adapter in the shape of a "Y" for division of the flow, to a mechanical pump, operating with a $20 \mathrm{~L} / \mathrm{min}$ flow, as shown in figure 1 . The inorganic and organic compounds were sampled simultaneously. Both samplers were installed at a height of 2 meters above the ground and were substituted every other day. This period for exchanging the samplers was based on a study of the air pollution in the city of São Paulo (Castanho and Artaxo [2]). In the São Paulo case, the samplers were changed every 12 hours, since the saturation of the filters leads to a reduction in the air flow, compromising the cutoff diameter. Taking into account the size of the city of Caxias do Sul, its fleet of vehicles and the number of industries compared to those of the city of São Paulo, the sampling period was taken to be from two to three days, since the problem of air pollution in Caxias do Sul is not so significant as in the metropolitan region of São Paulo.

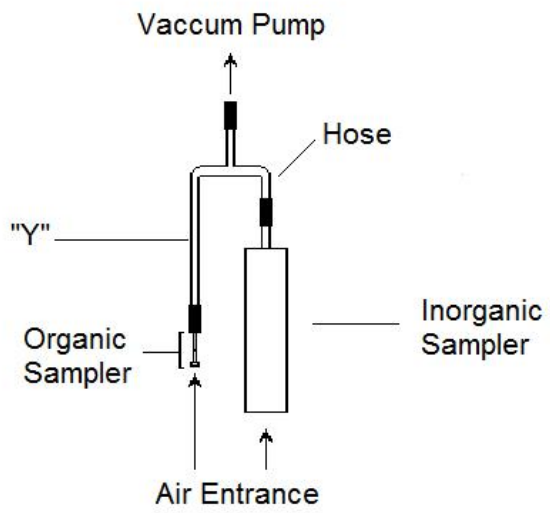

Figure 1: The inorganic and organic samplers.

\subsection{Inorganic particulate matter sampling and characterization}

The inhalable particulate matter was sampled using stacked filter units (SFU) [5, 6] on $47 \mathrm{~mm}$ diameter nuclepore polycarbonate filters, in two separate size fractions [7]. The inlet has an impactor stage designed to have 50\% collection efficiency at $10 \mathrm{~mm}$ equivalent aerodynamic diameter. The coarse particles $(2.5<$ $d_{p}<10 \mathrm{~mm}$ ) were collected in an $8.0 \mu \mathrm{m}$ pore size filter while fine particles 
$\left(d_{p}<2.5 \mathrm{~mm}\right)$ were collected on $0.4 \mu \mathrm{m}$ pore size filters. Mass concentrations of the fine and coarse modes were obtained gravimetrically with a $1 \mathrm{mg}$ sensitivity electronic microbalance, in a controlled atmosphere room $\left(20{ }^{\circ} \mathrm{C}, 50 \%\right.$ relative humidity, with fluctuations less than $10 \%$ of these set points). The filters were equilibrated in this room for $24 \mathrm{~h}$ before weighing. Electrostatic charges were controlled using radioactive sources. The concentration of $\mathrm{BC}$ on the fine fraction of the SFU was determined using a reflectance technique [8] that was calibrated using Monarch soot carbon standard in a smoke stain reflectometer, from Diffusion Systems, model M43D. These analyses were carried out at the laboratories of the Air Pollution Studies Group of the Physics Institute of the University of São Paulo (GEPA-IFUSP).

\subsection{Organic particulate matter sampling and characterization}

The cartridge for the organic compound extraction is made from a poly(methylene) syringe, stuffed with $1 \mathrm{~g}$ of cotton previously purified. This system of extraction is carried out according to the same principles applicable to solid phase extraction (SPE). The only difference is that, in this case, the mobile phase and the sample are the air that is forced to pass through the cartridge. For analysis the cartridges were covered with aluminum foil and stored at low temperature $\left(4^{\circ} \mathrm{C}\right)$ until the moment of extraction. The compounds that were adsorbed in the cartridges had been eluted with $5 \mathrm{~mL}$ of dichloromethane, and the organic fractions were immediately analyzed by gas chromatography with a flame ionization detector (GC/FID). The analyses for gas chromatography with detection via mass spectrometry (GC-MS) were carried out in the Analytical Center of the Technological Center of the Universidade Regional Integrada do Alto Uruguai e das Missões (URI-Campus de Erechim) in equipment Shimadzu GC-MS QP 5050. The GC/FID analysis were carried out in the Sanitation Laboratory (LASAN) of the Sanitation Institute (ISAM) of the University of Caxias do Sul (UCS) in a Perkin Elmer GC Autosystem XL equipment, under identical conditions to those used in the GC-MS, except for the parameters used for detection via mass spectrometry.

\section{Results}

The variation of the concentration of fine and coarse particulate matter $\left(\mathrm{PM}_{2.5}\right.$ and $\mathrm{PM}_{10}$ ) is presented in figure 2 while the variation of the concentration of fine and coarse black carbon (FBC and $\mathrm{CBC}$, respectively) is presented in figure 3 .

These data represent the variation of these concentrations in the sampling period. The acronyms on the horizontal axis of these figures represent the codifications of the samples. This codification was chosen, instead of the chronological order of sampling, to make the interpretation of the results more understandable. 


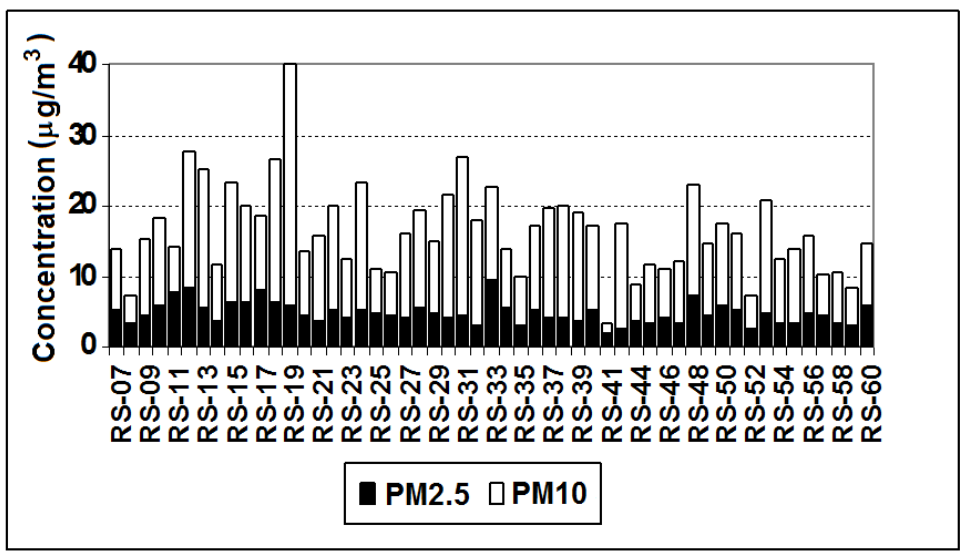

Figure 2: Variation of the concentration of fine and coarse particulate matter $\left(\mathrm{PM}_{2.5}\right.$ and $\left.\mathrm{PM}_{10}\right)$ during sampling period.

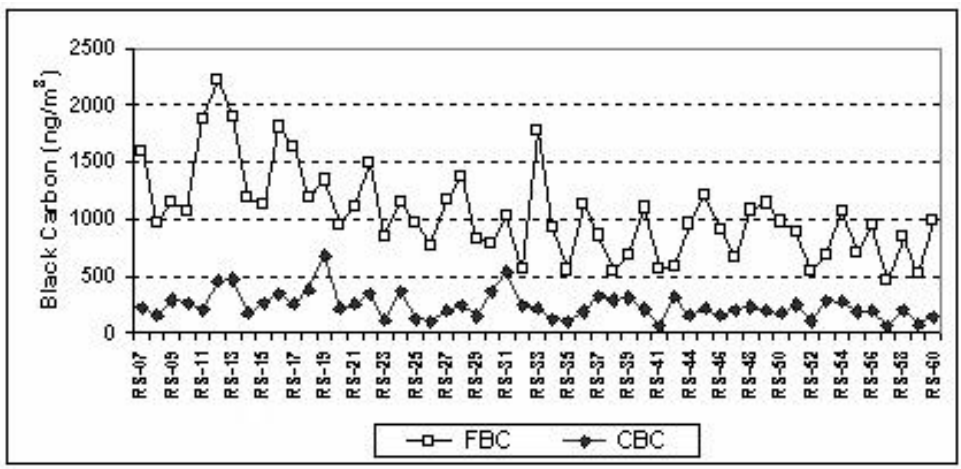

Figure 3: Variation of the concentration of fine and coarse black carbon (FBC and $\mathrm{CBC}$ ) during the sampling period.

A typical chromatogram of the organic fraction of sampled air is shown in figure 4 . The normalization of the areas under the chromatographic peaks by a tool of the operating software, allows one to determine the approximate concentrations of the detected compounds [9]. So in this context, it is possible to relate the increase or reduction of the area of a chromatographic peak of a particular compound, with the increase or reduction of its concentration in the sample. The identification of the chromatographic peaks (library of mass spectra of system $\mathrm{GC} / \mathrm{MS}$ ), with match quality greater or equal to $90 \%$, is also presented in figure 4.

Data in table 1 show that the date of detection corresponding to the smallest areas of the compounds $1 \mathrm{H}$-indene, neridol and diethyl hexylphthalate coincide with the date of maximum concentration of $\mathrm{PM}_{10}$. On the other hand, the date of detection of the highest concentrations of neridol and diethyl hexylphthalate 
Table 1: Relation among maximum and minimum concentrations of inorganic.

\begin{tabular}{ccccc}
\hline $\begin{array}{c}\text { Inorganic Particulate } \\
\text { Matter }\end{array}$ & $\begin{array}{c}\text { Maximum } \\
\text { Concentration }\end{array}$ & Date & $\begin{array}{c}\text { Minimum } \\
\text { Concentration }\end{array}$ & Date \\
\hline $\mathrm{PM}_{2.5}$ & $9.306 \mu \mathrm{g} / \mathrm{m}^{3}$ & $30 / 10$ & $1.908 \mu \mathrm{g} / \mathrm{m}^{3}$ & $18 / 10$ \\
$\mathrm{PM}_{10}$ & $34.219 \mu \mathrm{g} / \mathrm{m}^{3}$ & $27 / 09$ & $1.429 \mu \mathrm{g} / \mathrm{m}^{3}$ & $18 / 10$ \\
$\mathrm{FBC}$ & $2221.9 \mathrm{ng} / \mathrm{m}^{3}$ & $13 / 09$ & $456.8 \mathrm{ng} / \mathrm{m}^{3}$ & $02 / 01$ \\
$\mathrm{CBC}$ & $681.1 \mathrm{ng} / \mathrm{m}^{3}$ & $27 / 09$ & $61.9 \mathrm{ng} / \mathrm{m}^{3}$ & $18 / 10$ \\
\hline Volatile Organic & Maximum Area & Date & Minimum & Date \\
Compounds & $(\mathrm{au})$ & & Area $^{\mathrm{a}}(\mathrm{au})$ & \\
\hline $\begin{array}{c}\text { Decane chlorine } \\
\text { Eburnamonine }\end{array}$ & 739.94 & $23 / 09$ & 14.43 & $27 / 10$ \\
1H-indene & 440191.89 & $06 / 10$ & 7.97 & $13 / 09$ \\
Neridol & 2201.71 & $27 / 09$ & 6.1 & $23 / 10$ \\
$\begin{array}{c}\text { Diethyl } \\
\text { hexylphthalate }\end{array}$ & 1466.59 & $27 / 09$ & 3.94 & $18 / 10$ \\
Edulan & 9264.07 & $06 / 09$ & 22.83 & $25 / 10$ \\
$\begin{array}{c}\text { Diisopropyl } \\
\text { cyclohexane }\end{array}$ & 699.55 & $06 / 09$ & 76.03 & $11 / 10$ \\
\hline
\end{tabular}

${ }^{\mathrm{a}}$ Area under the chromatographic peak.

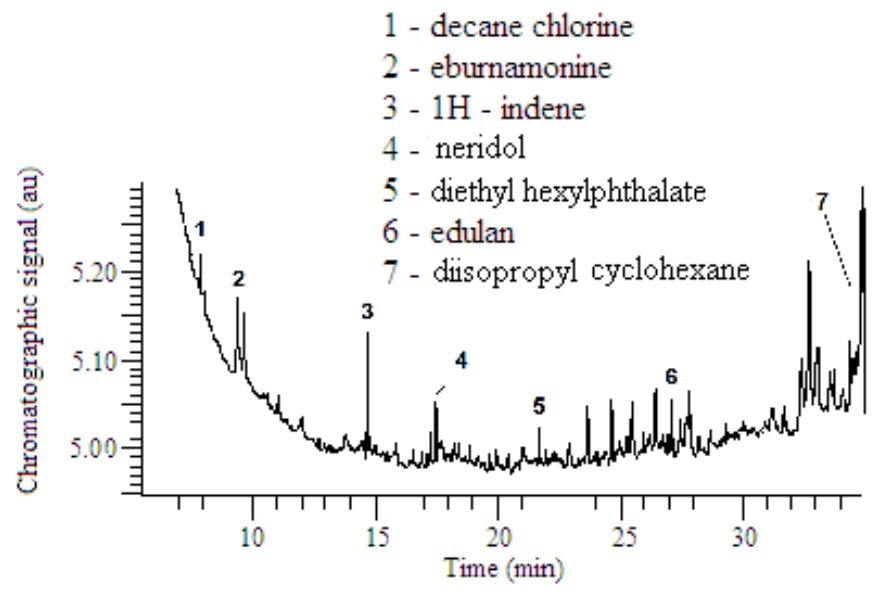

Figure 4: Chromatogram of the organic fraction of sampled air.

match the date of minimum concentration of $\mathrm{PM}_{10}$. These results suggest a possible effect of adsorption of organic compounds on the surface of the $\mathrm{PM}_{10}$. According to Andrade and co-workers [10] approximately $59 \%(\mathrm{~m} / \mathrm{m})$ of the $\mathrm{PM}_{10}$ corresponds to the dust of the ground that is composed basically of silica $\left(\mathrm{SiO}_{2}\right)$. The silica, in its purified form, is a very well known adsorbent, used for 
organic compound retention in liquid chromatography preparations. In this way, organic compounds, mainly the heterocyclic as $1 \mathrm{H}$-indeno, neridol and diethyl hexylphthalate, are more susceptible to the adsorption effect. The concentration in mass of dust from the ground in the $\mathrm{PM}_{2.5}$ is only $28 \%$ [10] and, obviously, the amount of silica is still smaller. These facts can explain the very low or almost nonexistent adsorption of organic compounds in the $\mathrm{PM}_{2.5}$. Another factor that contributes to the adsorption of organic compounds by the particulate matter is the size of particle, which varies from 2.5 to $15 \mu \mathrm{m}$ in $\mathrm{PM}_{10}$ and is smaller than $2.5 \mu \mathrm{m}$ in the $\mathrm{PM}_{2.5}$. [2, 10] In this context, it is possible that, due to their smaller particle size, the $\mathrm{PM}_{2.5}$ can rapidly reach a saturation level for the adsorption of voluminous organic molecules.

Still in Table 1, one can observe a coincidence between the dates of maximum concentrations of eburnamonine and FBC, suggesting that, in this

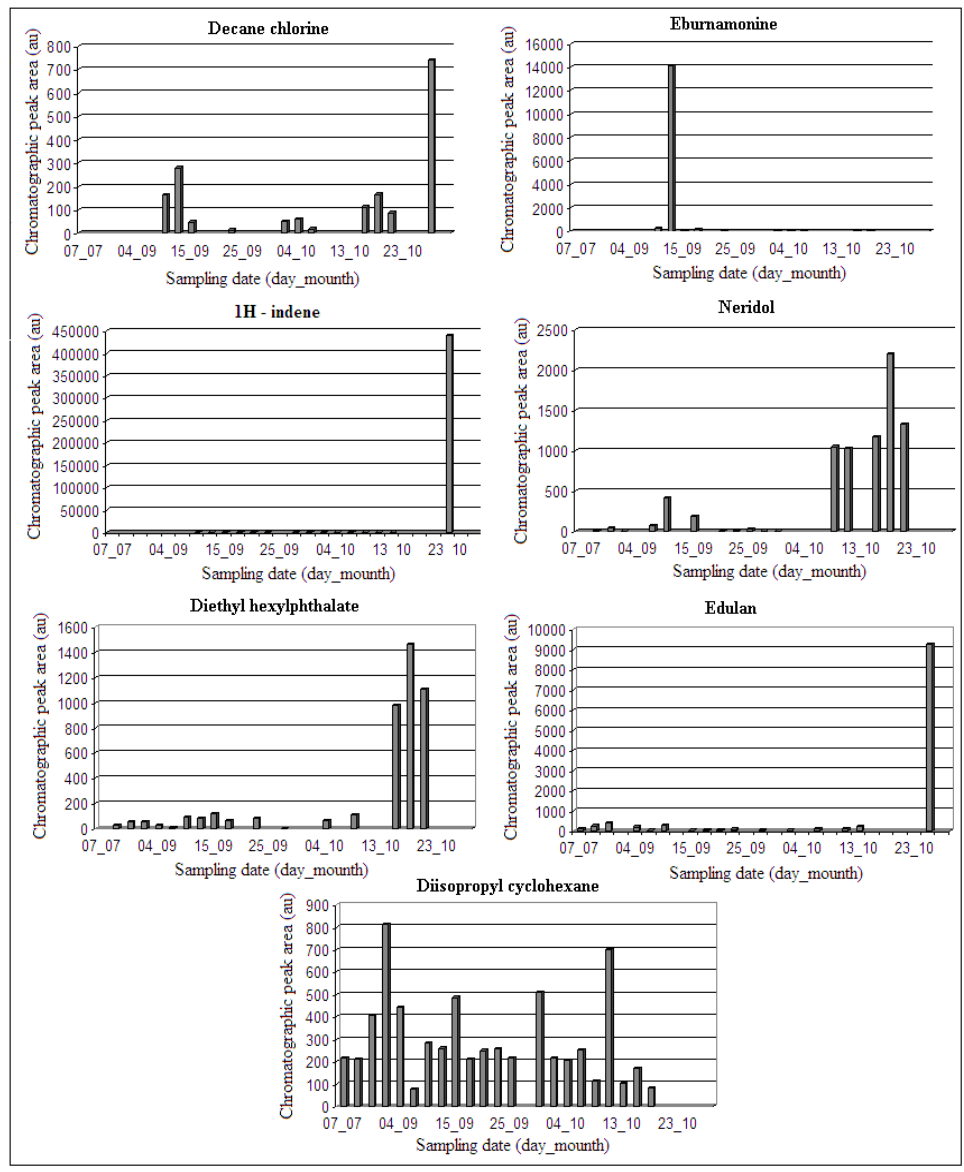

Figure 5: Variation of the area under the chromatographic peak of each VOC identified. 
case, the adsorption effect does not occur or it is not significant. Up to a certain point this is an unexpected result, since the BC particles are formed by nets of aromatical rings linked by short aliphatic chains or by sulfur or oxygen atoms, similar to the structure of eburnamonine.

The variation of the area under the chromatographic peak of each VOC identified (library of system GC-MS), during the whole sampling period, is presented in figure 5. Two important aspects seen in figure 5 are: (i) the regularity of detection of, practically, all the monitored compounds, obeying a pattern of minimum and maximum emissions that probably match with periods of lesser or greater industrial activity in the region studied; (ii) higher regularity of detection of Diisopropyl cyclohexane.

\section{Conclusions}

The preliminary results of this work suggest that, for some organic compounds, there is an adsorption effect by the coarse particulate matter. In particular, this effect is very pronounced for two organic compounds (neridol and diethyl hexylphthalate). The constant presence of admittedly carcinogenic compounds (such as decane chlorine and diisopropyl cyclohexane) or compounds suspected of having this effect (diethyl hexylphthalate) is particularly important. All these substances present high solubility in adipose tissue, that is, they cause a severe effect of bioaccumulation.

\section{Acknowledgements}

V. Villas-Boas, L. Moratelli and I. Nascimento would like to thank: GEPAIFUSP for loaning the equipments which made possible part of this research; CNPq, FAPERGS and UCS for financial support; and F.P. Missell for revisions of the manuscript.

\section{References}

[1] Macchione, M., Oliveira, A.P., Gallafrio, C.T., Muchão, F.P., Obara, M.T., Guimarães, E.T., Artaxo, P., King, M., Lorenzi-Filho, G., Junqueira, V.C.B. \& Saldiva, P.H.N., Acute effects of inhalable particles on the frog palate mucociliary epithelium. Environmental Health Perspectives, 107 (10), pp. 829-833, 1999.

[2] Castanho, A.D.A. \& Artaxo, P., Wintertime and summertime Sao Paulo aerosol source apportionment study. Atmospheric Environment, 35 (29), pp. 4889-4902, 2001.

[3] Vasconcellos, P.C., Carvalho, L.R.F. \& Pool, C.S., Volatile organic compounds inside urban tunnels of São Paulo city, Brazil. Journal of the Brazilian Chemical Society, 16 (6A), pp. 1210-1216, 2005. 
[4] Alves, C., Pio, C. \& Gomes, P., Determinação de hidrocarbonetos voláteis e semi-voláteis na atmosfera. Química Nova, 29 (3), pp. 477-488, 2006. Abstract in English. 2006,

[5] Parker, R.D., Buzzard, G.H., Dzubay, T.G. \& Bell, J.P., A two stage respirable aerosol sampler using Nuclepore filters in series. Atmospheric Environment, 11, pp. 617-621, 1977.

[6] Hopke, P.K., Xie, Y., Raunema, T., Biegalski, S., Landsberger, S., Maenhaut, W., Artaxo, P. \& Cohen, D., Characterization of the Gent Stacked Filter Unit PM10 Sampler. Aerosol Science and Technology, 27, pp. 726-735, 1997.

[7] John, W., Hering, S., Reischl, G. \& Sasaki, G., Characteristics of nuclepore filters with large pore size, II, filtration properties. Atmospheric Environment, 17, pp. 373-382, 1983.

[8] Reid, J.S., Hobbs, P.V., Liousse, C., Martins, J.V., Weiss, R.E. \& Eck T.F., Comparison of techniques for measuring short-wave absorption and black carbon content of aerosol from biomass burning in Brazil. Journal of Geophysical Research, 103 (D24), pp. 32031-32040, 1998.

[9] Nascimento, I.F., von Muhlen, C., Schossler, P., \& Caramão, E.B., Identification of some plasticizers compounds in landfill leachate. Chemosphere, 50, pp. 657-663, 2003.

[10] Andrade, M. F., Orsini, C. \& Maenhaut W., Relation between aerosol sources and meteorological parameters for inhalable atmospheric particles in Sao Paulo city, Brazil. Atmospheric Environment, 24 (14), pp. 2307$2315,1994$. 